Check for updates

Cite this: Phys. Chem. Chem. Phys., 2020, 22, 18882

Received 27th January 2020, Accepted 20th April 2020

DOI: $10.1039 / \mathrm{d} 0 \mathrm{cp} 00455 \mathrm{c}$

rsc.li/pccp

\title{
Temperature reversible synergistic formation of cerium oxyhydride and Au hydride: a combined XAS and XPDF study $\dagger$
}

\author{
Adam H. Clark, (D)*a Nadia Acerbi, ${ }^{\text {bc }}$ Philip A. Chater, (D) ${ }^{d}$ Shusaku Hayama, \\ Paul Collier, ${ }^{c}$ Timothy I. Hyde (iD ${ }^{c}$ and Gopinathan Sankar*a
}

\begin{abstract}
In situ studies on the physical and chemical properties of Au in inverse ceria alumina supported catalysts have been conducted between 295 and $623 \mathrm{~K}$ using high energy resolved fluorescence detection X-ray absorption near edge spectroscopy and $\mathrm{X}$-ray total scattering. Precise structural information is extracted on the metallic Au phase present in a $0.85 \mathrm{wt} \% \mathrm{Au}$ containing inverse ceria alumina catalyst (ceria/Au/ alumina). Herein evidence for the formation of an $\mathrm{Au}$ hydride species at elevated temperature is presented. Through modelling of total scattering data to extract the thermal properties of Au using Grüneisen theory of volumetric thermal expansion it proposed that the Au Hydride formation occurs synergistally with the formation of a cerium oxyhydride. The temperature reversible nature, whilst remaining in a reducing atmosphere, demonstrates the activation of hydrogen without consumption of oxygen from the supporting ceria lattice.
\end{abstract}

\section{Introduction}

Ceria is widely used, particularly within auto-exhaust catalysis, ${ }^{1-4}$ due to enhanced oxygen storage capacity. The nature of cerium ions within the fluorite ceria phase to be stable in both Ce(III) and $\mathrm{Ce}(\mathrm{Iv})$ oxidation states allowing for the storage and release of oxygen for oxidation reactions, often promoted by supported noble metal nanoparticles. ${ }^{5-8}$ The promotion of the ceria reduction by platinum group metals (PGMs) has been explained by various mechanisms: (1) the spill-over of hydrogen from the PGM surface onto the ceria, ${ }^{9-11}$ (2) reverse oxygen spill-over from the ceria towards the PGM ceria interface, ${ }^{12-14}$ (3) direct metal-support interactions, either through the strong metal support interaction ${ }^{15-17}$ or electronic metal support interaction. ${ }^{18-20}$

The strong metal-support interaction has long been studied for its ability to change the chemisorption properties of platinum group metals (PGM) supported on metal oxide supports, commonly $\mathrm{SiO}_{2}, \mathrm{ZnO}, \mathrm{CeO}_{2}$ or $\mathrm{TiO}_{2} \cdot{ }^{15-17,21-25}$ In many systems the interaction between metallic particles and the support directly

\footnotetext{
${ }^{a}$ Department of Chemistry, University College London, 20 Gordon Street, London WC1H OAJ, UK. E-mail: adam.clark@psi.ch,g.sankar@ucl.ac.uk

${ }^{b}$ Wolfson Catalysis Centre, Inorganic Chemistry Laboratory, University of Oxford, South Parks Road, Oxford, OX1 3QR, UK

'Johnson Matthey Technology Centre, Blount's Court, Sonning Common, Reading RG4 9NH, UK

${ }^{d}$ Diamond Light Source, Harwell Science \& Innovation Campus, Didcot, Oxfordshire OX11 ODE, UK

† Electronic supplementary information (ESI) available. See DOI: 10.1039/d0cp00455c
}

influences their catalytic behavior. The term strong metal-support interaction has also been related to the electronic metal-support interaction $^{18-20}$ whereby there can be a small transfer of electrons from the support to metal or vice versa. This $\delta \pm$ charge can play an important role in the catalytic reactivity through van der Waals interactions. In the work of Acerbi et $a .^{26-28}$ the strong metal support interaction on ceria coated, alumina supported PGMs was modelled using Junction theory. They proposed that the PGM promotes the formation of oxygen vacancies in ceria by the donation of electrons to the supported PGM Fermi level. With increasing work function of the PGM, the barrier for oxygenvacancy formation was demonstrated to decrease. The role of alumina has also been noted to stabilise ceria, and ceria-zirconia solid solutions. ${ }^{29-31}$ In particular the inhibition of the ceria sintering has been observed resulting in the stabilization of highly dispersed ceria. ${ }^{32}$

While $\mathrm{Au}$ is classically described as a noble metal due to its relative inert behaviour towards oxidation or the absorption of gas phase molecules, Au nanoparticles have shown to be catalytically active particularly when supported on oxide supports. ${ }^{33-40}$ The interaction with the support materials has been demonstrated to result in a partial electron transfer from the support to the supported $\mathrm{Au}^{41,42}$ and can lead to the anchoring of Au onto the surface. ${ }^{43}$ During oxidative dehydrogenation catalysis on ceriasupported catalysts, Au hydride formation has previously been proposed to be an important intermediate. However, the characterisation of solid phase Au hydride presents a significant challenge. ${ }^{44}$ Previously Au hydrides have been only shown to be 
stable as a diatomic molecule with limited evidence for the presence of a stable solid phase hydride under catalytic conditions. ${ }^{33,34,41}$

$\mathrm{Au}$ materials have recently found interest for gas sensing applications where embedded Au ceria alumina materials have shown to be highly sensitive to gas phase hydrogen in localised surface plasmon resonance studies. ${ }^{45-47}$ The dissociation of hydrogen on $\mathrm{Au}$ has also been observed resulting in previous work identifying a metastable Au-hydride. ${ }^{46}$ Whilst the optical properties of $\mathrm{Au}$ and $\mathrm{NiO}$ nanoparticles supported on $\mathrm{SiO}_{2}$ have suggested an interaction between $\mathrm{H}_{2}$ and Au causing a change in optical transmittance at elevated temperatures in $\mathrm{a}_{2}$ containing atmosphere. $^{48}$

Previously, attempts have been made to determine the interaction of hydrogen with Au using XAS demonstrating a limited sensitivity to the bonding of hydrogen to $\mathrm{Au} .{ }^{49}$ Elsewhere, IR experiments, after $\mathrm{H} / \mathrm{D}$ exchange have suggested that hydrogen dissociates only on under coordinated $\mathrm{Au}(0)^{50}$ sites. Inelastic neutron scattering (INS) experiments have shown the presence of Ce hydride ${ }^{51}$ like species and proposed the presence of $\mathrm{Au}$ hydrides on ceria supported catalysts. ${ }^{52,53}$ However, INS studies necessitate the quenching of the sample to low temperatures. Our previous work on the formation of a cerium oxyhydride species demonstrated that this species is lost upon cooling. ${ }^{54}$

Whilst there have been numerous studies that point towards the potential formation of complex hydride species in Au and ceria containing materials, to date there are very limited examples of studies probing the dynamic structure of such materials. Therefore, to gain further understanding of the reactivity of supported $\mathrm{Au}$ catalysts we have used a combined XAS, at the Ce $\mathrm{L}_{3}$-edge and $\mathrm{X}$-ray total scattering study. By extracting the difference X-ray pair distribution function (dxPDF), the dynamic local structural evolution of supported $\mathrm{Au}$ catalysts can be elucidated during interaction with hydrogen. Using dxPDF in combination with high energy resolution fluorescence detection X-ray absorption near

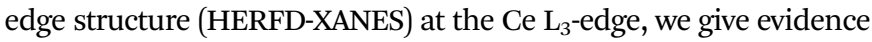
for the co-formation of a metastable cerium oxyhydride and $\mathrm{Au}$ hydride phases within a hydrogen atmosphere. The presence of a high temperature Au hydride is demonstrated through the application of Grüneisen model ${ }^{55}$ to volumetric lattice expansion.

\section{Experimental}

The $15 \mathrm{wt} \%$ ceria/0.85 wt $\%$ Au/alumina inverse catalyst and $15 \mathrm{wt} \%$ ceria/alumina support material used in this study are the same as reported in an earlier publication where details of the catalyst preparation and temperature programmed reduction are given. ${ }^{27}$ The catalyst composition is assumed from the synthesis procedure. Estimates of the sample composition has also been obtained from XRD analysis given in $\mathrm{ESI} \dagger \mathrm{S} 1$ and $\mathrm{T} 1$ which agrees with the intended composition.

To monitor the oxidation state of the cerium phase present within the ceria phase of the sample HERFD-XANES at the $\mathrm{Ce}_{3}$ edge was employed. The high energy resolution of the technique allows for the accurate determination of the fraction of the reduced state $\mathrm{Ce}$ (III) present within the sample to be extracted.

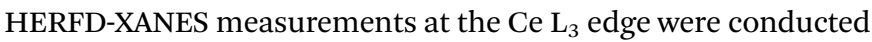

at I20-scanning beam-line at the Diamond Light Source ${ }^{56}$ on the ceria/Au/alumina systems through monitoring the intensity of the Ce $\mathrm{L} \alpha_{1}$ photo emission line with the X-ray emission spectrometer fixed at $4840 \mathrm{eV}$. The incident beam was monochromatised using a $\operatorname{Si}(111)$ 4-bounce monochromator with a spot size on the sample of $400 \times 300 \mu \mathrm{m}(H \times V)$. The incident energy was scanned between 5680 and $5850 \mathrm{eV}$. A Rh coated collimating mirror was used with subsequent harmonic rejection was achieved using a Si coated mirror. The X-ray emission spectrometer operated in the Johann configuration with a $1 \mathrm{~m}$ diameter Rowland circle and was equipped with 3 spherically bent analyser crystals of $100 \mathrm{~mm}$ diameter. In a typical experiment, about $12 \mathrm{mg}$ of the sample was mixed with $50 \mathrm{mg}$ of fumed silica, pressed into a pellet and loaded in to an in situ cell. The in situ reaction chamber used for the XAS work is very similar to the one published by Nguyen et $a .^{57}$ This cell is made of quartz glass which has beam entry exit for transmission geometry and another port at 90 degrees for fluorescence measurements. All these ports contain sealed Kapton windows. The sample is loaded into the cell from the top which is sealed by a KF40 flange. The sample holder and a port for the thermocouple were attached to the top of the flange along with ports for gas in and gas out. Pellet samples are mounted onto the sample holder, with the thermocouple placed strategically close to the sample and not interfering with the beam. Once the sample is loaded, $\mathrm{N}_{2}$ gas was used to flush out all the gases present in the system for $30 \mathrm{~min}$. Subsequently the system was equilibrated under $3.5 \% \mathrm{H}_{2} / \mathrm{N}_{2}$ gas for $30 \mathrm{~min}$ prior to heating to $623 \mathrm{~K}$ at $\mathrm{K} \mathrm{min}^{-1}$ followed by cooling to room temperature under the same atmosphere.

X-ray total scattering were conducted at ID15-1 beam-line at the Diamond Light Source. Measurements were performed at refined sample to detector distance of $198.3 \mathrm{~mm}$ with a photon energy of $76.69 \mathrm{keV}$. A 2D PerkinElmer image plate detector with each frame being collected for $1 \mathrm{~s}$ and with 5 frames were averaged together in post-processing. Conversion to integrated line spectra being performed with $\mathrm{DAWN}^{58,59}$ and Fourier Transformation performed using xPDFsuite. ${ }^{60}$ Samples were loaded into fused quartz capillaries with an internal diameter of $0.9 \mathrm{~mm}$. A hot air blower directly below the sample was used to heat to $623 \mathrm{~K}$ at a ramp rate of $10 \mathrm{~K} \mathrm{~min}^{-1}$. Samples were then cooled at $10 \mathrm{~K} \mathrm{~min}^{-1}$ to room temperature. The recorded measurement of temperature was taken from the hot air blower and logged throughout the

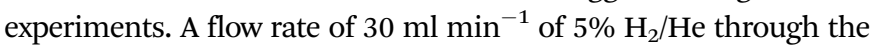
capillary was utilised throughout and controlled using Gilmont Accucal flowmeters. In both experiments leak testing of all Swagelok connections was performed using Swagelok Snoop ${ }^{\mathbb{R}}$ liquid leak detector with an inert gas flow. The sample powder was pressed and sieved with a sieve fraction of $100-150 \mu \mathrm{m}$ prior to loading into the quartz capillary without dilution.

\section{Results and discussion}

\section{Analysis of the Ce $\mathrm{L}_{3}$-edge XAS experiments}

Experiments following the oxidation state of cerium were performed using the HERFD-XANES technique on the ceria/ Au/alumina sample by measuring the excitation of the $2 \mathrm{p}^{3 / 2}$ 

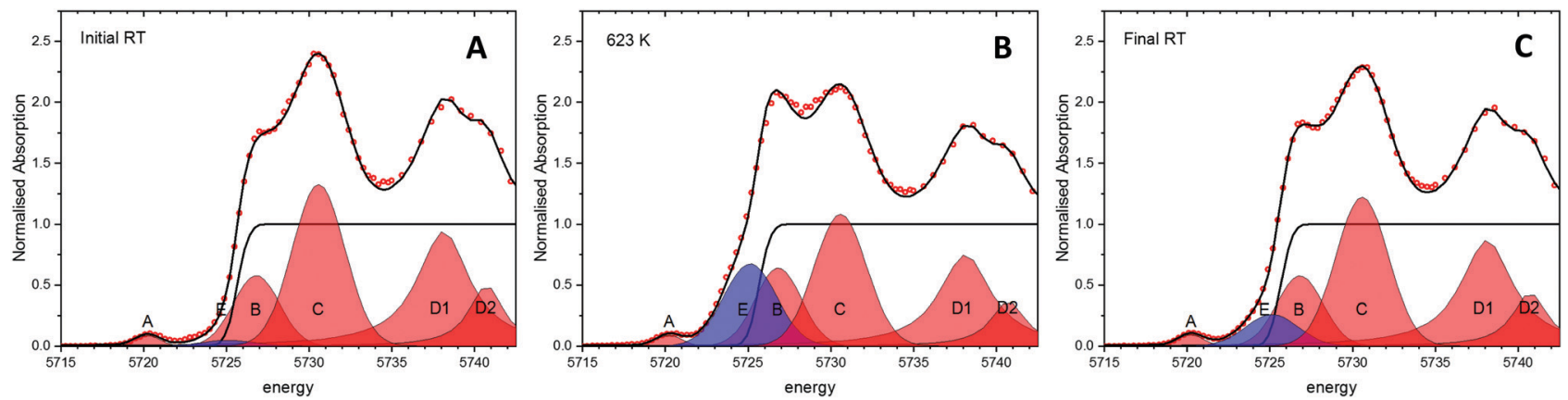

Fig. 1 Experimental HERFD-XANES spectra and results relating to partially reduced ceria. Example of the peak fitting methodology undertaken on the normalised HERFD-XANES spectra of ceria samples. The red peaks give the Ce(IV) contribution whilst the blue gives the Ce(III) contribution during heating and cooling in a $3.5 \% \mathrm{H}_{2} / \mathrm{He}$ atmosphere. The three spectra relate to the initial starting material at room temperature (A), at $623 \mathrm{~K}(\mathrm{~B})$ and after cooling back to room temperature (C) of the ceria/Au/alumina sample.

electrons to unoccupied $4 \mathrm{f}$ and $5 \mathrm{~d}$ states. The XAS spectra collected at room temperature, prior to heating, at $623 \mathrm{~K}$ and at final room temperature, after heating in hydrogen are shown in Fig. 1. Analysis of the XANES structure was performed using a peak fitting methodology. While peak fitting examples for the

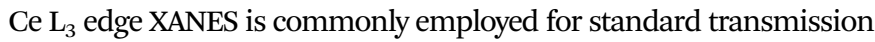
XANES analysis, ${ }^{61-64}$ such an approach has not routinely been employed for analysis of HERFD-XANES. The association of the peaks to Ce(III) and Ce(IV) species was made in comparison to a NIST ceria reference material and previously reported associations and electronic transitions in the literature, ${ }^{54,64-66}$ and illustrated in Fig. 1. Here feature $\mathrm{A}$ is a pre-edge feature associated to the partially occupied $4 \mathrm{f}$ electron within the fluorite ceria structure while $\mathrm{B}$ and $\mathrm{C}$ are associated to the crystal-field splitting within the cubic fluorite structure of the $2 \mathrm{p} \rightarrow 4 \mathrm{f}^{0}, 5 \mathrm{~d}$ transition. D1 and D2 relate to the unscreened excited states exhibiting crystal field splitting, and $\mathrm{E}$, to a singlet for the $2 \mathrm{p} \rightarrow 4 \mathrm{f}^{1} 5 \mathrm{~d}$ for Ce(III) ion. The fraction of $\mathrm{Ce}(\mathrm{III})$ is then calculated from the ratio of associated peak areas.

The initial starting material was assigned as almost fully $\mathrm{Ce}(\mathrm{Iv})$. The presence of substantial Ce(III) as a result of heating the sample in $\mathrm{a}_{2}$ containing atmosphere is shown by the peak growing centred around $5725 \mathrm{eV}$, illustrated as peak E shaded blue. Therefore it can be noted that the exposure to hydrogen leads to the formation of Ce(III). However, as with our previous findings on a high surface area ceria material, ${ }^{54}$ upon cooling the majority of formed $\mathrm{Ce}(\mathrm{III})$ is re-oxidised to $\mathrm{Ce}(\mathrm{Iv})$ without the presence of an oxidising atmosphere. This effect can be clearly seen by the fact that area of peak E, shaded blue, at $623 \mathrm{~K}$ is greater than after cooling to RT. The degree of formation of $\mathrm{Ce}$ (III) is estimated by consideration of the ratio of peak areas of the $\mathrm{Ce}(\mathrm{III})$ and $\mathrm{Ce}(\mathrm{Iv})$ associated contributions.

$$
[\mathrm{Ce}(\mathrm{III})]=\frac{A[\mathrm{Ce}(\mathrm{III})]}{A[\mathrm{Ce}(\mathrm{III})]+A[\mathrm{Ce}(\mathrm{IV})]}
$$

From this method the initial proportion of $\mathrm{Ce}(\mathrm{III})$ is found to be $1 \%$, whilst at $623 \mathrm{~K} 26 \pm 2 \% \mathrm{Ce}(\mathrm{III})$ is formed. These results are in line with our previous publication ${ }^{54}$ suggesting a stoichiometry of $\mathrm{HCe}_{4} \mathrm{O}_{8}$ at $623 \mathrm{~K}$. After cooling in $\mathrm{H}_{2}$ there is approximately $7 \%$ of the $\mathrm{Ce}(\mathrm{III})$ remaining. This may be due to remaining a partial extraction of oxygen from the ceria lattice or by remaining surface or subsurface hydroxyl groups. However, it can be noted that the majority of the Ce(III) formation $(\sim 19 \%)$ is due to a temperature reversible process and therefore not as a consequence of reduction by removal of oxygen from the lattice.

\section{Analysis of the xPDF experiments}

To probe the correlation between the expansion of the ceria lattice and the effect of supported Au, xPDF experiments were performed on the ceria coated alumina supported Au sample and a similar sample without the presence of Au. Due to the complexities of accurately refining the Bragg diffraction data with the alumina phase, correction by subtraction of an alumina diffraction pattern collected under the sample experimental conditions was performed prior to Fourier transform to the real space. The temperature of each measurement was matched to within $0.1 \mathrm{~K}$ and subtracted from the integrated total scattering data, as illustrated in Fig. 2A. Subtraction of the Ceria phase from the integrated total scattering data is not possible due to the dynamically changing nature of ceria under a reducing atmosphere; partial reduction of ceria results in an expanded fluorite lattice structure. As such a fitting model was created to accurately refine the ceria and metallic Au phases. Fitting was performed between 1.7 and $20 \AA$ in real space using PDFGui. ${ }^{67}$ The lattice parameters and atomic displacement parameters were refined during the fitting procedure. A typical fit to the initial room temperature differential xPDF dataset using a biphasic metallic Au and fluorite ceria phases is shown in Fig. 2B, here the Au component is explicitly shown at the bottom to illustrate its contribution to the differential pair distribution function $G(r)$. The remaining peaks in the dxPDF pattern are given by the ceria phase contribution, which as expected dominates the pattern after removing the alumina component. By this method it is possible to follow the evolution of the respective $\mathrm{Au}$ and ceria components during heating and cooling in the $5 \% \mathrm{H}_{2} / \mathrm{He}$ atmosphere. Typical fits for several temperatures are shown in the ESI $\dagger$ S2-S10. A plot comparing the Ceria and Au lattice parameters and the rw for all fitted data sets for the ceria/Au/ alumina is shown as Fig. S11 (ESI $\dagger$ ). 

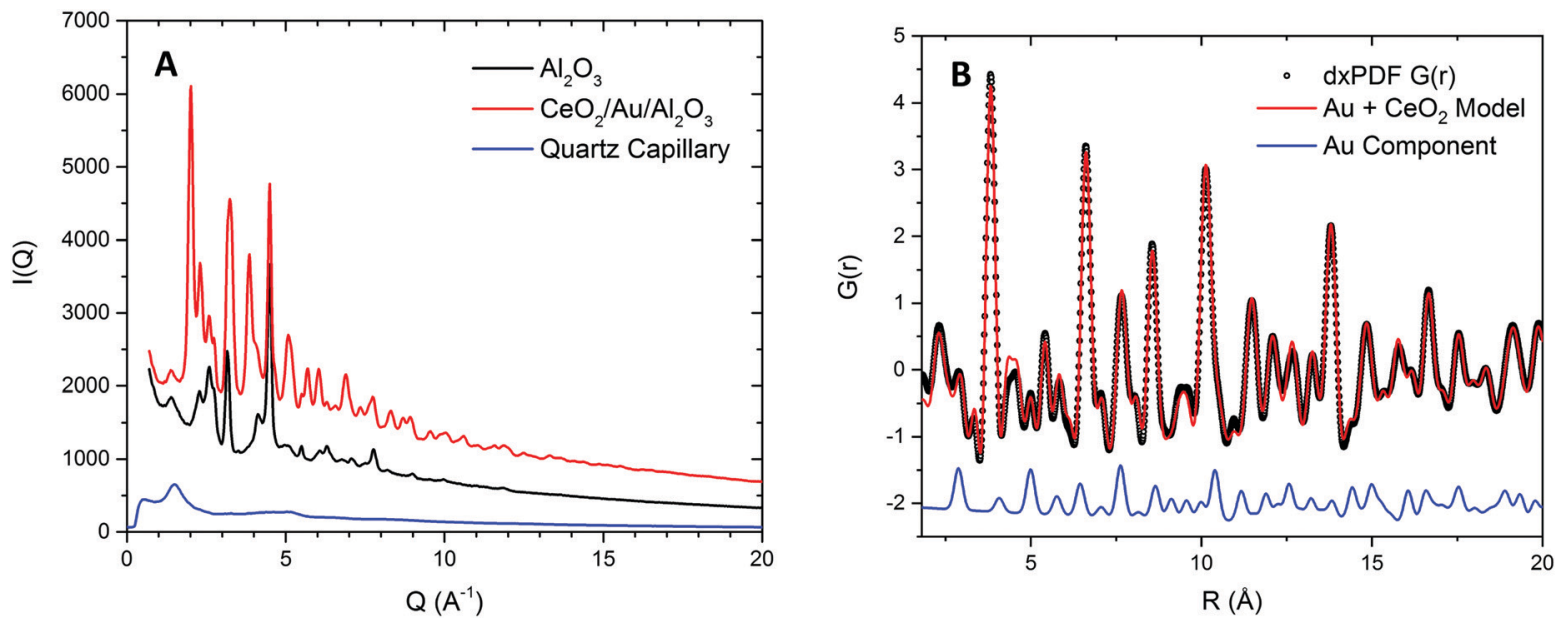

Fig. 2 Experimental DxPDF patterns, alumina subtraction and Fourier Transformation recorded at room temperature. (A) Integrated total scattering pattern relating to: a ceria alumina support Au inverse catalyst sample, a gamma alumina support and fused quartz capillary sample environment; illustrating the process for correction to arrive at the differential XPDF containing the fluorite ceria and metallic Au components. (B) Example fit to the initial differential xPDF G(r) for a biphase model containing fluorite ceria and metallic Au components over a fitting region of 1.8 to $20 \AA$. The metallic Au component contribution is highlighted below the data to illustrate the presence of the metallic Au phase within the extracted differential xPDF G(r). Typical fit residual, $r_{\mathrm{w}}=0.1$

The extracted ceria lattice parameters are shown in Fig. 3 for the ceria/alumina and ceria/Au/alumina samples demonstrating a noticeable expansion in the ceria lattice is found heating above $450 \mathrm{~K}$. The expansion seen in the ceria lattice can be rationalised by two competing processes. Firstly, linear thermal expansion of the fluorite lattice and secondly by the formation of $\mathrm{Ce}(\mathrm{III})$ ions within the fluorite lattice.

The latter causes expansion due to the fact that $\mathrm{Ce}(\mathrm{III})$ ions are larger than $\mathrm{Ce}(\mathrm{Iv})$ ions. Fig. 3A gives the ceria lattice parameter, as a function of temperature, during heating in $5 \%$ $\mathrm{H}_{2} / \mathrm{He}$ atmosphere for both samples. Here it can be seen that during heating in hydrogen, there is a significant inflection in the ceria lattice parameter at approximately $475 \mathrm{~K}$ for both the ceria/Au/alumina and ceria/alumina samples. This behaviour has been associated to the formation of $\mathrm{Ce}$ (III) ions within the ceria lattice due to the interaction with hydrogen. ${ }^{54}$ A non-linear lattice expansion cannot be explained solely by thermal expansion of the ceria lattice. However, the rate of the Ce(III) formation is noted to be somewhat faster for the Au containing sample. As such, it can be proposed that the presence of $\mathrm{Au}$ promotes the formation of $\mathrm{Ce}(\mathrm{III})$ ions within the ceria lattice. However direct estimation of the Ce(III) fraction not possible from dxPDF and is more precisely determined from the Ce $\mathrm{L}_{3}$ edge XAS experiments.

When considering the cooling cycle, shown in Fig. 3B, it is evident that the ceria lattice contracts to near its initial starting conditions for both the ceria/Au/alumina and ceria/alumina samples. Coupled with the findings from XAS that there is substantial reoxidation of the Ce(III) to Ce(Iv) during cooling we propose that there is a formation of a meta-stable cerium oxyhydride phase induced by the interaction of hydrogen with the ceria lattice in the same mechanism as previously reported. ${ }^{54}$ Our previous study demonstrated that the formation of $\mathrm{Ce}(\mathrm{III})$ formation in ceria under mild conditions by
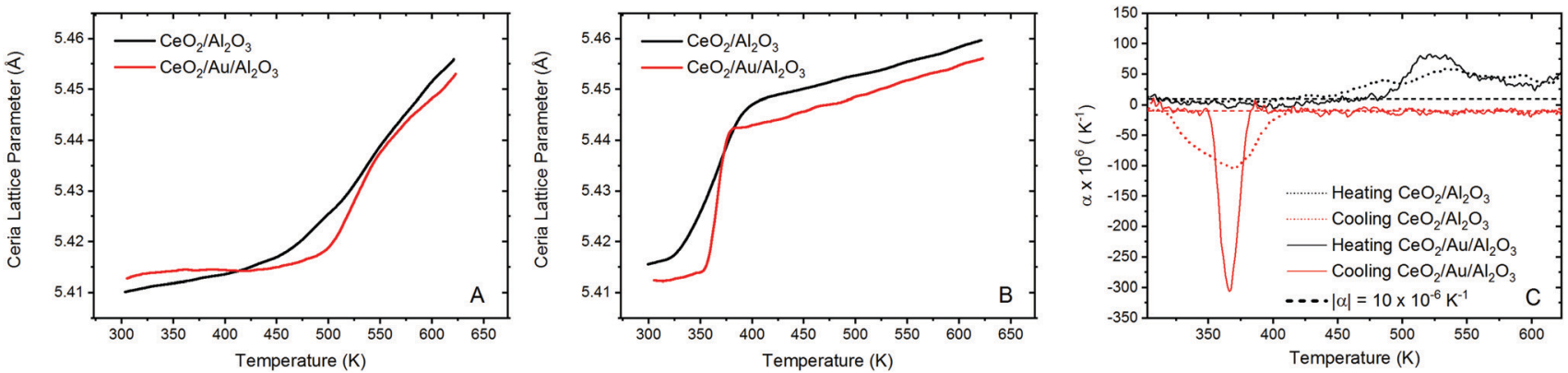

Fig. 3 Experimental DxPDF results showing the extracted ceria lattice parameter. The ceria/alumina and ceria/Au/alumina ceria lattice parameter refinements are given in black and red respectively for experiments conducted during heating in a $5 \% \mathrm{H}_{2} / \mathrm{He}$ atmosphere for the heating $(A)$ and cooling (B) in $5 \% \mathrm{H}_{2} / \mathrm{He}(\mathrm{C})$ instantaneous expansion coefficient during heating and cooling for the ceria/alumina (dotted lines) and ceria/Au/alumina (solid lines) samples. Dashed lines give the expected thermal expansion coefficient of ceria, $\alpha=10 \times 10^{-6} \mathrm{~K}^{-1}$, expansion in excess is associated to chemical change of the sample. 
the interaction with hydrogen does not necessitate the removal of oxygen from the lattice.

The calculation of the instantaneous lattice expansion coefficient is given in Fig. 3C. The instantaneous expansion coefficient is defined by;

$$
\alpha(T)=\frac{1}{L} \frac{\mathrm{d} l}{\mathrm{~d} T}
$$

here $\alpha(T)$ gives the instantaneous linear thermal expansion coefficient, $L$ is the room temperature lattice parameter, $\mathrm{d} l / \mathrm{d} T$ gives the derivative of the change in ceria lattice parameter with temperature. The thermal expansion of ceria has been widely studied previously ${ }^{68,69}$ and has been found to be approximately $10 \times 10^{-6} \mathrm{~K}^{-1}$. Any non-linear expansion of the lattice above this value is associated to chemical change within the ceria lattice. In this case such non-linear expansion is associated to the formation of $\mathrm{Ce}(\mathrm{III})$ ions within the lattice by the inclusion of hydrogen as previously shown in our earlier work ${ }^{54}$ identifying the temperature reversible formation of a cerium oxyhydride species.

\section{Application of the Debye model for internal energy}

Whilst the cerium $\mathrm{L}_{3}$ edge XAS and the lattice parameter refinements form XPDF provide extensive information on the nature of the ceria component of the support, we also exploited the XPDF data to extract further information on the behavior of the $\mathrm{Au}$ phase. Modelling of the thermal dependence on the Au unit cell volume expansion through consideration of the Debye temperature can be achieved by employing a Grüneisen model. ${ }^{70-72}$ The unit cell volume for the $\mathrm{Au}$ phase can be expressed as;

$$
V(T)=\frac{V_{t}}{2 k_{0} a_{\mathrm{v}}}\left(1+2 k_{0}-\sqrt{1-\frac{4 k_{0} U}{Q_{0}}}\right)
$$

where $V_{t}$ is the unit cell volume at a reference temperature, $t$, here chosen to the value obtained at $294 \mathrm{~K}$ (room temperature), $a_{\mathrm{v}}$ is the determined from the ratio of $V_{t} / V_{0}, k_{0}$ is a function of the derivative of the bulk modulus, $k_{0}$, with pressure, whilst $Q_{0}$ relates to the Grüneisen parameter and $U$ is given by the internal energy.

$$
\begin{gathered}
k_{0}=\frac{\left(\frac{\mathrm{d} K_{0}}{\mathrm{~d} P}-1\right)}{2} \\
Q_{0}=\frac{K_{0} V_{0}}{\gamma_{\mathrm{G}}}
\end{gathered}
$$

Here the value of $\frac{\mathrm{d} K_{0}}{\mathrm{~d} P}$ has been set from Dewaele et $a l^{73}$ at 6 giving $k_{0}$ to be 2.5. The internal energy is determined for consideration of the Debye model and is described by the eqn (5) where $\theta_{\mathrm{G}}$ is the Debye temperature, $R$ the gas constant, $n$ is given by the number of atoms in the formula unit, $T$ describes the temperature on absolute scale.

$$
U=9 n R T\left(\frac{T}{\theta_{\mathrm{D}}}\right) \int_{0}^{\frac{\theta_{\mathrm{D}}}{T}} \frac{x^{3}}{\mathrm{e}^{x}-1} \mathrm{~d} x
$$

Extension of this allows for the Debye temperature to be used directly to determine the dynamic contribution to the atomic displace parameter of $\mathrm{Au}$, given in eqn (6). ${ }^{72,74}$

$$
\left\langle u_{\text {dynamic }}{ }^{2}\right\rangle=\frac{3 \hbar^{2}}{m k_{\mathrm{B}} \theta_{\mathrm{D}}}\left(\frac{1}{4}+\left(\frac{T}{\theta_{\mathrm{D}}}\right)^{2} \int_{0}^{\frac{\theta_{\mathrm{D}}}{T}} \frac{x}{\mathrm{e}^{x}-1} \mathrm{~d} x\right)
$$

Here $m$ is defined as the atomic mass and $k_{\mathrm{B}}$ the Boltzmann constant. Any contribution from the static disordering or instrumental broadening can be accounted by a constant correction term, eqn (7), where $U_{\text {iso }}$ is the refined atomic displacement parameter for isotropic thermal displacement from analysis of the dxPDF data. This constant offset term refined to $0.0008 \pm 0.0001 \AA^{2}$.

$$
U_{\text {iso }}=\left\langle u_{\text {dynamic }}{ }^{2}\right\rangle+\left\langle u_{\text {static+instrumental }}{ }^{2}\right\rangle .
$$

Modelling of the lattice volume expansion of $\mathrm{Au}$ as a function of temperature using the Grüneisen model, eqn (2), demonstrates a strong agreement between the expansion determined from the experimental scattering data and theoretically determined lattice volume. The Debye temperature, $\theta_{\mathrm{D}}$, was refined to be $170 \pm 4 \mathrm{~K}$, as shown in Fig. 4A. This value is in close agreement to previous experimental work demonstrating a Debye temperature for $\mathrm{Au}$ of $165 \mathrm{~K}^{75-77}$

In addition to these findings, it was possible to refine the value of $V_{0}$ from the modelling of the volumetric lattice expansion. Here it is determined that $V_{0}$ is equal to $66.6 \AA^{3}$, or a lattice parameter of $4.05 \AA$ which is contracted as compared to bulk Au $(4.078 \AA)$. Elsewhere it has been noted that there is a large contraction in the lattice volume in the surface of fcc nanocrystals $^{78,79}$ and as such this would indicate that the Au is present in nanocrystalline form in this sample.

Through the modelling of refined atomic displacement parameter it can be shown that there is a strong agreement between the Debye model for internal energy and the atomic displacement parameter between 293 and $475 \mathrm{~K}$, shown in Fig. 4B. Above this there can be seen to be a deviation from the model which results in a lower than predicted $U_{\text {iso }}$ value; this implies a higher Debye temperature in this region and is proposed to be due to the formation of an Au hydride species. Typically hydride species have elevated Debye temperatures when considered against their metallic counterparts. ${ }^{80}$ Evidence for surface gold hydride species has also previously been reported elsewhere in Au/ceria catalysts ${ }^{42,52,53,81}$ and therefore it could be taking place at the Au surface or the Au-ceria interface. For the $\mathrm{Au}$ containing sample is was previously reported that the $\mathrm{H}_{2}$ dissociation rate on the Au metal surface is readily possible at temperature in excess of $420 \mathrm{~K}^{27}$ and that the noted temperature where $\mathrm{H}_{2}$ can be dissociated by the $\mathrm{Au}$ surface corresponded well with an observed peak of hydrogen update in TPR measurements. The findings from the DxPDF analysis would suggest that the dissociation of hydrogen leads to physical changes in the structure of the Au lattice.

Further to these results, there can be seen to be a remarkable agreement in the temperature between the formation of the metastable cerium oxyhydride phase $^{54}$ and the proposed formation of the surface Au hydride species at approximately 

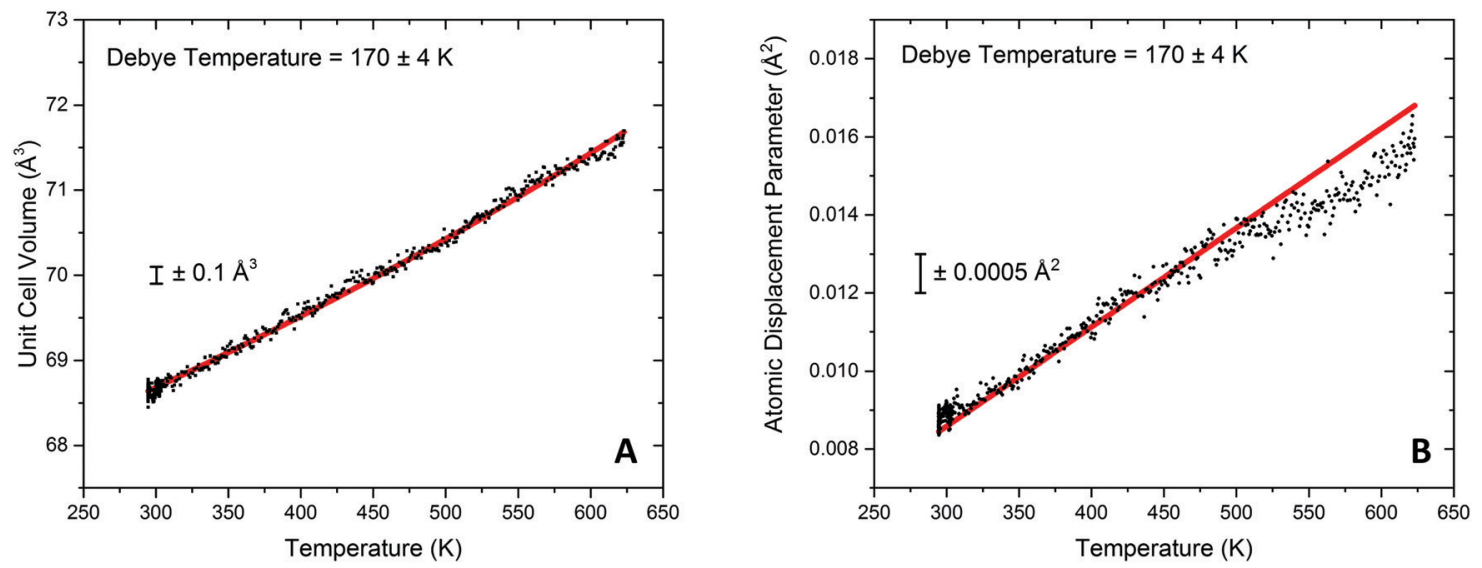

Fig. 4 Fitting of unit cell volume and atomic displacement parameters extracted from differential xPDF analysis relating to the metallic Au component. (A) Fitting of the Au unit cell volume during heating of the ceria/Au/alumina sample using Grüneisen model for the volumetric thermal expansion is shown in red. The extracted Au Debye temperature, $170 \pm 4 \mathrm{~K}$, is indicated on the plot. (B) Illustration of the fitting to the atomic displacement parameter extracted from differential XPDF analysis is shown in red. The dynamic contribution is accounted for through the Debye model.

$475 \mathrm{~K}$. This finding and the comparison with the ceria lattice parameter refinements during heating, shown in Fig. 3A, suggests that the proposed Au hydride forms coincidental to the cerium oxyhydride phase. As such, it can be proposed that $\mathrm{Au}$ promotes the formation of cerium oxyhydride species through the interaction of hydrogen with the supported $\mathrm{Au}$ nanoparticles.

Analysis of the cooling phase of the experiment was also undertaken in a similar way and is shown in Fig. 5. Here the fitting was truncated to be between $375 \mathrm{~K}$ and $623 \mathrm{~K}$ due to the inflection in both the lattice parameter data and the refined atomic displacement parameter at approximately $375 \mathrm{~K}$. It should be noted that whilst in the heating data no significant deviation from the Grüneisen model for the lattice volume was observed, a clear step resulting in a decrease in the lattice volume can be seen on cooling.
The gradient of the cooling prior to $375 \mathrm{~K}$ can also be observed to be significantly different from the heating data. For clarity Fig. 5A displays the model for the heating data in red superimposed upon the cooling data; the blue curve gives the fitting to the truncated cooling data. Furthermore, it can be noted that below $350 \mathrm{~K}$ the lattice volume follows very closely the model of the heating data. This would suggest that changes in the lattice volume are not an effect of particle sintering of the $\mathrm{Au}$ phase. Refinement of $V_{0}$ from the modelling of the volumetric lattice expansion yields a lattice volume of $67.6 \AA^{3}$, or a lattice parameter of $4.07 \AA$. This is a noted increase as compared to the value of $V_{0}$ obtained from the heating data and would further indicate that there is a formation of an $\mathrm{Au}$ hydride species on exposure to hydrogen at elevated temperatures. The refinement of the Debye temperature yields a slightly elevated value, $173 \mathrm{~K}$. However, the uncertainty on this is relatively high
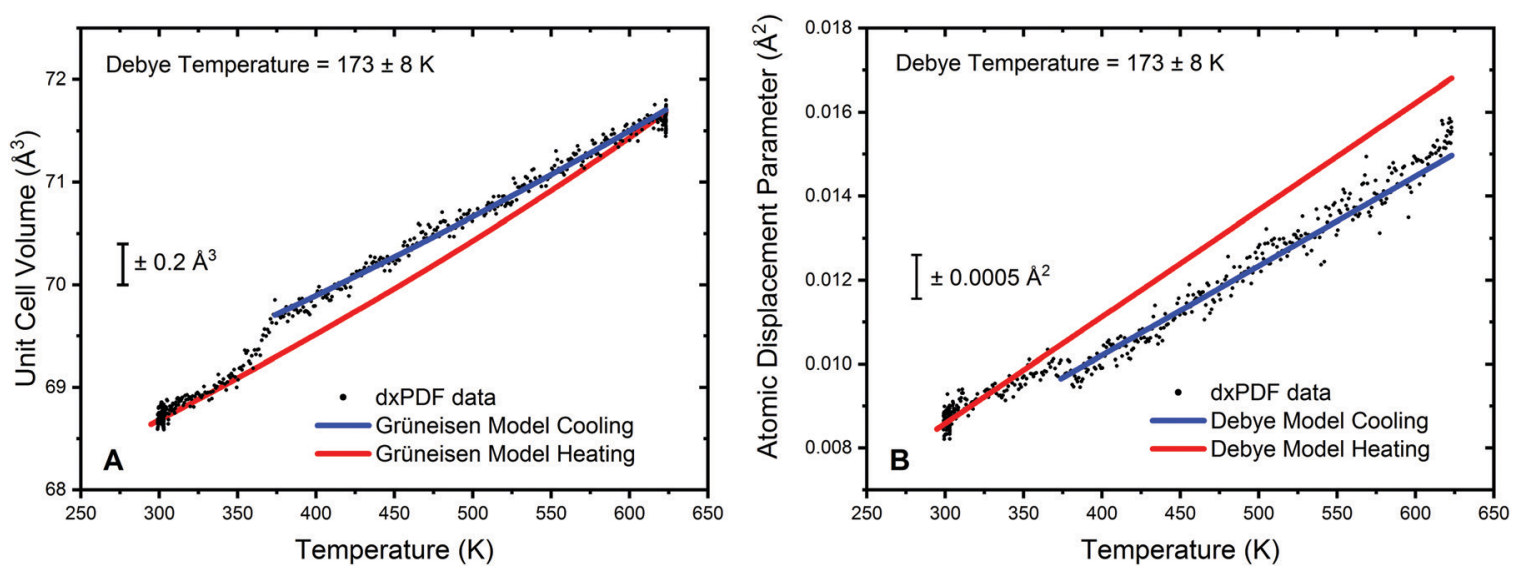

Fig. 5 Fitting of unit cell volume and atomic displacement parameters extracted from differential xPDF analysis relating to the metallic Au component. (A) Fitting of the Au unit cell volume during cooling of the ceria/Au/alumina sample using Grüneisen model for the volumetric thermal expansion is shown in blue. The model refined from the heating data is given superimposed in red. The extracted Au Debye temperature from the cooling in $5 \% \mathrm{H}_{2} / \mathrm{He}$, $173 \pm 8 \mathrm{~K}$, is indicated on the plot. (B) Illustration of the fitting to the atomic displacement parameter extracted from cooling differential xPDF analysis is shown in blue. The model for the heating data is show superimposed in red. The dynamic contribution to the atomic displacement parameter is accounted for through the Debye model. 
due to the truncation of the data range and as such can only tentatively be noted as increased in respect to the cooling data.

Analysis of the atomic displacement parameter reveals a step like change in disorder when cooling and is shown in Fig. 5B. The modelling of the data for the cooling phase is truncated due to the step increase in the refined atomic displacement parameter observed at approximately 350 K. From Fig. 5B it can be observed that the dynamic contribution to the atomic displacement parameter during cooling is marginally lower than the heating phase and can be modelled by an increase in the Debye temperature. The static contribution (and instrumental contribution) to the atomic displacement parameter is the same for both heating and cooling data. Therefore, the decrease in disorder is suggested to be well modelled by a slight increase in the refined Debye temperature and further alludes to an Au hydride species being present. Below $350 \mathrm{~K}$, the data is seen to closely follow the refined model of the heating portion of the experiment. Therefore, it can be proposed that the formation of $\mathrm{Au}$ hydride is only stable in this system above approximately $350 \mathrm{~K}$.

\section{Conclusions}

In summary, we have shown how analysis of lattice and atomic displacement parameters from differential X-ray total scattering methods combined with the element specificity of HERFDXANES can be exploited to provide significant insight into the interactions of hydrogen with the ceria/Au/alumina catalysts studied here. Using dxPDF to probe the physical and chemical properties of individual phases present within a complex multiphase material elucidates the role of $\mathrm{Au}$ in promoting the formation of a cerium oxyhydride species. The application of the Grüneisen model for volumetric lattice expansion and the Debye model we have determined the Debye temperature of Au to be $170 \pm 4 \mathrm{~K}$. Furthermore, whilst modelling of the refined atomic displacement parameter through consideration of the internal energy using the Debye model, a clear deviation from the atomic displacement model occurs at temperatures exceeding $475 \mathrm{~K}$ under a partial $\mathrm{H}_{2}$ atmosphere. This has been interpreted as arising from the formation of an Au hydride species.

The interplay between the structural changes in the $\mathrm{Au}$ and support ceria has been explored through consideration of the ceria lattice expansion and the formation of $\mathrm{Ce}(\mathrm{III})$ ions upon heating in the reducing $5 \% \mathrm{H}_{2} / \mathrm{He}$ atmosphere between 293 and $623 \mathrm{~K}$. Above $475 \mathrm{~K}$, the lattice parameter of the ceria is observed to expand non-linearly. This is associated initially to the formation $\mathrm{Ce}(\mathrm{III})$ ions within the fluorite lattice by the inclusion of hydrogen to form a metastable cerium oxyhydride species. Upon cooling, in a reducing atmosphere the reduced $\mathrm{Ce}(\mathrm{III})$ species revert almost completely back to Ce(Iv) concurrent with the apparent loss of the Au hydride.

The formation the cerium oxyhydride species was demonstrated to be promoted in the presence of $\mathrm{Au}$ and to form coincidentally to the proposed Au hydride species. These findings may explain why $\mathrm{Au} /$ ceria materials have been demonstrated to be active in hydrogenation and hydrochlorination reactions.

\section{Conflicts of interest}

There are no conflicts to declare.

\section{Acknowledgements}

We thank Diamond Light Source for access to beamline I15-1 (EE15696) and beamline I20-scanning (SP16508) that contributed to the results presented here. We thank EPSRC and Johnson Matthey Plc for a Case Award (AHC EPSRC: 1635837).

\section{Notes and references}

1 A. Bueno-López, Appl. Catal., B, 2014, 146, 1-11.

2 A. Trovarelli, C. De Leitenburg, M. Boaro and G. Dolcetti, Catal. Today, 1999, 50, 353-367.

3 J. Kašpar, P. Fornasiero and N. Hickey, Catal. Today, 2003, 77, 419-449.

4 R. J. Farrauto and R. M. Heck, Catal. Today, 1999, 51, 351-360.

5 S. E. Golunski, H. A. Hatcher, R. R. Rajaram and T. J. Truex, Appl. Catal., B, 1995, 5, 367-376.

6 F. Morfin, T.-S. Nguyen, J.-L. Rousset and L. Piccolo, Appl. Catal., B, 2016, 197, 2-13.

7 Z. Mohamed, V. D. B. C. Dasireddy, S. Singh and H. B. Friedrich, Appl. Catal., B, 2016, 180, 687-697.

8 T.-S. Nguyen, F. Morfin, M. Aouine, F. Oise Bosselet, J.-L. Rousset and L. Piccolo, Catal. Today, 2015, 253, 106-114.

9 G. Dutta, U. V. Waghmare, T. Baidya and M. S. Hegde, Chem. Mater., 2007, 19, 6430-6436.

10 Y. Yao and D. W. Goodman, J. Mol. Catal. A: Chem., 2014, 383-384, 239-242.

11 V. Sharma, P. A. Crozier, R. Sharma and J. B. Adams, Catal. Today, 2012, 180, 2-8.

12 F. R. Negreiros and S. Fabris, J. Phys. Chem. C, 2014, 118, 21014-21020.

13 G. N. Vayssilov, Y. Lykhach, A. Migani, T. Staudt, G. P. Petrova, N. Tsud, T. Skála, A. Bruix, F. Illas, K. C. Prince, V. Matolín, K. M. Neyman and J. Libuda, Nat. Mater., 2011, 10, 310-315.

14 Y. Men, H. Gnaser, C. Ziegler, R. Zapf, V. Hessel and G. Kolb, Catal. Lett., 2005, 105, 35-40.

15 A. Bruix, J. A. Rodriguez, P. J. Ramírez, S. D. Senanayake, J. Evans, J. B. Park, D. Stacchiola, P. Liu, J. Hrbek and F. Illas, J. Am. Chem. Soc., 2012, 134, 8968-8974.

16 S. J. Tauster, S. C. Fung and R. L. Garten, J. Am. Chem. Soc., 1978, 100, 170-175.

17 S. J. Tauster, Acc. Chem. Res., 1987, 20, 389-394.

18 Z. Ma, X. Xiong, C. Song, B. Hu and W. Zhang, RSC Adv., 2016, 6, 51106-51110.

19 P. Hu, Z. Huang, Z. Amghouz, M. Makkee, F. Xu, F. Kapteijn, A. Dikhtiarenko, Y. Chen, X. Gu and X. Tang, Angew. Chem., Int. Ed., 2014, 53, 3418-3421.

20 C. T. Campbell, Nat. Chem., 2012, 4, 597-598.

21 T. Lunkenbein, J. Schumann, M. Behrens, R. Schlögl and M. G. Willinger, Angew. Chem., Int. Ed., 2015, 54, 4544-4548. 
22 Y. Lykhach, S. M. Kozlov, T. Skála, A. Tovt, V. Stetsovych, N. Tsud, F. Dvořák, V. Johánek, A. Neitzel, J. Mysliveček, S. Fabris, V. Matolín, K. M. Neyman and J. Libuda, Nat. Mater., 2016, 15, 284-288.

23 X. Y. Shi, W. Zhang, C. Zhang, W. T. Zheng, H. Chen and J. G. Qi, J. Microsc., 2016, 262, 203-215.

24 L. Deng, H. Miura, T. Shishido, S. Hosokawa, K. Teramura and T. Tanaka, Chem. Commun., 2017, 53, 6937-6940.

25 H. Tang, Y. Su, B. Zhang, A. F. Lee, M. A. Isaacs, K. Wilson, L. Li, Y. Ren, J. Huang, M. Haruta, B. Qiao, X. Liu, C. Jin, D. Su, J. Wang and T. Zhang, Sci. Adv., 2017, 3, e1700231.

26 N. Acerbi, S. C. Tsang, S. Golunski and P. Collier, Chem. Commun., 2008, 1578-1580.

27 N. Acerbi, S. C. E. Tsang, G. Jones, S. Golunski and P. Collier, Angew. Chem., Int. Ed., 2013, 52, 7737-7741.

28 N. Acerbi, S. Golunski, S. C. Tsang, H. Daly, C. Hardacre, R. Smith and P. Collier, J. Phys. Chem. C, 2012, 116, 13569-13583.

29 R. Di Monte and J. Kašpar, J. Mater. Chem., 2005, 15, 633-648.

30 A. Piras, A. Trovarelli and G. Dolcetti, Appl. Catal., B, 2000, 28, L77-L81.

31 E. C. Su, C. N. Montreuil and W. G. Rothschild, Appl. Catal., 1985, 17, 75-86.

32 M. Fer Andez-García, A. Martínez-Arias, A. Iglesias-Juez, C. Belver, A. B. Hungría, J. C. Conesa and J. Soria, J. Catal., 2000, 194, 385-392.

33 H.-J. Zhai, B. Kiran and L.-S. Wang, J. Chem. Phys., 2004, 121, 8231. 34 X. Wu, Z. Qin, H. Xie, R. Cong, X. Wu, Z. Tang and H. Fan, J. Chem. Phys., 2010, 133, 044303.

35 M. Shekhar, J. Wang, W. S. Lee, W. D. Williams, S. M. Kim, E. A. Stach, J. T. Miller, W. N. Delgass and F. H. Ribeiro, J. Am. Chem. Soc., 2012, 134, 4700-4708.

36 R. Si, J. Tao, J. Evans, J. B. Park, L. Barrio, J. C. Hanson, Y. Zhu, J. Hrbek and J. A. Rodriguez, J. Phys. Chem. C, 2012, 116, 23547-23555.

37 D. Tibiletti, A. Amieiro-Fonseca, R. Burch, Y. Chen, J. M. Fisher, A. Goguet, C. Hardacre, P. Hu and D. Thompsett, J. Phys. Chem. B, 2005, 109, 22553-22559.

38 Z. K. Han, Y. G. Wang and Y. Gao, Chem. Commun., 2017, 53, 9125-9128.

39 W. Deng and M. Flytzani-Stephanopoulos, Angew. Chem., Int. Ed., 2006, 45, 2285-2289.

40 G. M. Mullen, E. J. Evans, I. Sabzevari, B. E. Long, K. Alhazmi, B. D. Chandler and C. B. Mullins, ACS Catal., 2017, 7, 1216-1226.

41 A. Sanchez, S. Abbet, U. Heiz, W. D. Schneider, H. Häkkinen, R. N. Barnett and U. Landman, J. Phys. Chem. A, 1999, 103, 9573-9578.

42 X. Wang and L. Andrews, Angew. Chem., Int. Ed., 2003, 42, 5201-5206.

43 N. Ta, J. Liu, S. Chenna, P. A. Crozier, Y. Li, A. Chen and W. Shen, J. Am. Chem. Soc., 2012, 134, 20585-20588.

44 M. Wang, F. Wang, J. Ma, M. Li, Z. Zhang, Y. Wang, X. Zhang and J. Xu, Chem. Commun., 2014, 50, 292-294.

45 N. A. Joy, M. I. Nandasiri, P. H. Rogers, W. Jiang, T. Varga, S. V. N. T. Kuchibhatla, S. Thevuthasan and M. A. Carpenter, Anal. Chem., 2012, 84, 5025-5034.
46 D. Sil, K. D. Gilroy, A. Niaux, A. Boulesbaa, S. Neretina and E. Borguet, ACS Nano, 2014, 8, 7755-7762.

47 C. Wadell, S. Syrenova and C. Langhammer, ACS Nano, 2014, 8, 11925-11940.

48 D. Buso, G. Busato, M. Guglielmi, A. Martucci, V. Bello, G. Mattei, P. Mazzoldi and M. L. Post, Nanotechnology, 2007, $18,7$.

49 N. Guo, B. R. Fingland, W. D. Williams, V. F. Kispersky, J. Jelic, W. N. Delgass, F. H. Ribeiro, R. J. Meyer and J. T. Miller, Phys. Chem. Chem. Phys., 2010, 12, 5678-5693.

50 M. Boronat, P. Concepción and A. Corma, J. Phys. Chem. C, 2009, 113, 16772-16784.

51 Z. Wu, Y. Cheng, F. Tao, L. Daemen, G. S. Foo, L. Nguyen, X. Zhang, A. Beste and A. J. Ramirez-Cuesta, J. Am. Chem. Soc., 2017, 139, 9721-9727.

52 I. P. Silverwood, S. M. Rogers, S. K. Callear, S. F. Parker, C. R. A. Catlow, D. Andreeva, J. El Fallah, L. Hilaire, F. Le Normand, E. Quemere, G. N. Sauvion and O. Touret, Chem. Commun., 2016, 52, 533-536.

53 R. Juárez, S. F. Parker, P. Concepción, A. Corma and H. García, Chem. Sci., 2010, 1, 731-738.

54 A. H. Clark, K. A. Beyer, S. Hayama, T. I. Hyde and G. Sankar, Chem. Mater., 2019, 31, 7744-7751.

55 E. Grüneisen, Ann. Phys., 1912, 344, 257-306.

56 S. Diaz-Moreno, S. Hayama, M. Amboage, A. Freeman, J. Sutter and G. Duller, J. Phys.: Conf. Ser., 2009, 190, 012038.

57 H. K. D. Nguyen, G. Sankar and R. A. Catlow, J. Porous Mater., 2017, 24, 421-428.

58 M. Basham, J. Filik, M. T. Wharmby, P. C. Y. Chang, B. El Kassaby, M. Gerring, J. Aishima, K. Levik, B. C. A. Pulford, I. Sikharulidze, D. Sneddon, M. Webber, S. S. Dhesi, F. Maccherozzi, O. Svensson, S. Brockhauser, G. Náray and A. W. Ashton, J. Synchrotron Radiat., 2015, 22, 853-858.

59 J. Filik, A. W. Ashton, P. C. Y. Chang, P. A. Chater, S. J. Day, M. Drakopoulos, M. W. Gerring, M. L. Hart, O. V. Magdysyuk, S. Michalik, A. Smith, C. C. Tang, N. J. Terrill, M. T. Wharmby and H. Wilhelm, J. Appl. Crystallogr., 2017, 50, 959-966.

60 X. Yang, P. Juhas, C. L. Farrow and S. J. L. Billinge, 2014, arXiv:1402.3163v3 [cond-mat], https://arxiv.org/abs/1402. 3163, accessed 08 29, 2019.

61 S. Phokha, S. Pinitsoontorn, P. Chirawatkul, Y. Poo-arporn and S. Maensiri, Nanoscale Res. Lett., 2012, 7, 425.

62 V. Fernandes, I. L. Graff, J. Varalda, L. Amaral, P. Fichtner, D. Demaille, Y. Zheng, W. H. Schreiner and D. H. Mosca, J. Electrochem. Soc., 2011, 159, K27-K33.

63 T. S. Wu, Y. Zhou, R. F. Sabirianov, W. N. Mei, Y. L. Soo and C. L. Cheung, Chem. Commun., 2016, 52, 5003-5006.

64 H. R. Marchbank, A. H. Clark, T. I. Hyde, H. Y. Playford, M. G. Tucker, D. Thompsett, J. M. Fisher, K. W. Chapman, K. A. Beyer, M. Monte, A. Longo and G. Sankar, ChemPhysChem, 2016, 17, 3494-3503.

65 C. Paun, O. V. Safonova, J. Szlachetko, P. M. Abdala, M. Nachtegaal, J. Sa, E. Kleymenov, A. Cervellino, F. Krumeich 
and J. A. Van Bokhoven, J. Phys. Chem. C, 2012, 116, 7312-7317.

66 A. V. Soldatov, T. S. Ivanchenko, S. Della Longa, A. Kotani, Y. Iwamoto and A. Bianconi, Phys. Rev. B: Condens. Matter Mater. Phys., 1994, 50, 5074-5080.

67 C. L. Farrow, P. Juhas, J. W. Liu, D. Bryndin, E. S. Boin, J. Bloch, T. Proffen and S. J. L. Billinge, J. Phys.: Condens. Matter, 2007, 19, 335219.

68 T. Hisashige, Y. Yamamura and T. Tsuji, J. Alloys Compd., 2006, 408-412, 1153-1156.

69 S. Sameshima, M. Kawaminami and Y. Hirata, J. Ceram. Soc. Jpn., 2002, 110, 597-600.

70 D. G. Isaak, O. L. Anderson and H. Oda, Phys. Chem. Miner., 1992, 19, 10-120.

71 I. Suzuki and O. L. Anderson, J. Phys. Earth, 1983, 31, 125-138.

72 A. Nakatsuka, M. Shimokawa, N. Nakayama, O. Ohtaka, H. Arima, Ma. Okube and A. Yoshiasa, Am. Mineral., 2011, 96, 1593-1605.
73 A. Dewaele, P. Loubeyre and M. Mezouar, Phys. Rev. B: Condens. Matter Mater. Phys., 2004, 70, 094112.

74 E. S. Božin, V. Petkov, P. W. Barnes, P. M. Woodward, T. Vogt, S. D. Mahanti and S. J. L. Billinge, J. Phys.: Condens. Matter, 2004, 16, S5091.

75 K. Sadaiyandi, Mater. Chem. Phys., 2009, 115, 703-706.

76 A. Balerna and S. Mobilio, Phys. Rev. B: Condens. Matter Mater. Phys., 1986, 34, 2293-2298.

77 Y. D. Qu, X. L. Liang, X. Q. Kong and W. J. Zhang, Phys. Met. Metallogr., 2017, 118, 528-534.

78 S. Xiong, S. Y. Lee and I. C. Noyan, J. Appl. Crystallogr., 2019, 52, 262-273.

79 D. S. Q. Jiang, L. H. Liang and D. S. Zhao, J. Phys. Chem. B, 2001, 105, 6275-6277.

80 I. Jacob, A. Wolfy and M. H. Y. Mintz, Solid State Commun., 1981, 40, 877-879.

81 M. Manzoli, A. Chiorino, F. Vindigni and F. Boccuzzi, Catal. Today, 2012, 181, 62-67. 